\title{
Tingkat Difusi Oksigen Selama Periode Blind Feeding Budidaya Intensif Udang Vaname (Litopenaeus vannamei)
}

\author{
Heri Ariadi ${ }^{1 *}$, Abdul Wafi², Supriatna ${ }^{3}$, Muhammad Musa ${ }^{3}$
}

${ }^{1}$ Program Studi Budidaya Perairan, Fakultas Perikanan Universitas Pekalongan

Jl. Sriwijaya No. 3 Pekalongan 51119 Jawa Tengah

${ }^{2}$ Fakultas Sains dan Teknologi Universitas Ibrahimy Situbondo

JI. Sumberejo Kec. Banyuputih Kabupaten Situbondo 68374 Jawa Timur

${ }^{3}$ Fakultas Perikanan dan Ilmu Kelautan Universitas Brawijaya

Jl. Veteran Ketawanggede Kec. Lowokwaru Kota Malang 65145 Jawa Timur

*email : ariadi_heri@yahoo.com

DOI: https://doi.org/10.21107/rekayasa.v14i2.10737

\begin{abstract}
The diffusion process is a limiting factor that key plays for the oxygen transfer mechanism in the pond water column. The purpose of this study was to determine of oxygen diffusion rate during the blind feeding period of intensive shrimp culture of vaname (L. vannamei). This research was conducted for 30 days blind feeding period of intensive vaname shrimp culture, the research using concept of ex-pose facto causal design. Furthermore, the oxygen diffusion rate is calculated mathematically and a regression test is carried out on the associated water quality parameters. During the blind feeding period, the oxygen diffusion rate fluctuates and dynamically, with a diffusion rate ranging from 0.015$0.028 \mathrm{mgO}_{2} / \mathrm{L} / \mathrm{hour}$. This condition is followed by a stabilizing and optimum condition of pond water quality parameter values throughout in the aquaculture. Diurnal periodically, the oxygen diffusion mechanism has an influence on the level of oxygen solubility in ponds. This relationship is modeled by the equation $Y=0.006+0.002 x$. This means that for each diffusion transfer increase of $1 \mathrm{mgO}_{2} / \mathrm{L} / \mathrm{hour}$, there will be an oxygen increase in the ponds of $0.002 \mathrm{mg} / \mathrm{L}$. The conclusion of this study is that the oxygen diffusion rate during the blind feeding period of intensive vaname shrimp culture obtained an average at $0.020 \mathrm{mgO}_{2} / \mathrm{L} / \mathrm{hour}$, ranging from 0.018-0.023 $\mathrm{mgO} / \mathrm{L} /$ hour for 30 days of culture. From the results of this study, it is hoped that research can be developed study regarding of mechanisms, dynamics, and the effect of oxygen diffusion on the intensive shrimp farming ecology.
\end{abstract}

Keywords: blind feeding, oxygen diffusion, water quality, Litopenaeus vannamei

\section{PENDAHULUAN}

Udang vaname (Litopenaeus vannamei) merupakan salah satu spesies komoditas budidaya perikanan yang sangat digemari oleh para pembudidaya udang di Indonesia. Udang vaname (L. vannamei) dapat dibudidayakan baik secara tradisional, semi intensif, maupun intensif (Edhy et a.l, 2010). Budidaya udang vaname pola intensif adalah suatu konsep budidaya yang berorientasi pada peningkatan kapasitas produktifitas panen berdasarkan kemampuan tingkat daya dukung yang tersedia (Syah et al., 2017). Pada budidaya intensif, oksigen terlarut adalah salah satu indikator lingkungan penting yang berperan terhadap kapasitas daya dukung ekosistem tambak selama masa periode blind

\section{Article History:}

Received: August, 24 ${ }^{\text {th }}$ 2020; Accepted: May, $15^{\text {th }} 2021$. Rekayasa ISSN: 2502-5325 has been Accredited by Ristekdikti (Arjuna) Decree: No. 23/E/KPT/2019 August 8th, 2019 effective until 2023 feeding budidaya. Blind feeding adalah periode budidaya udang dengan pemberian pakan buta selama 30 hari awal masa budidaya karena prosentase survival rate dan biomassa udang yang belum diketahui dengan pasti (Edhy et al., 2010).

Selama periode blind feeding budidaya udang, proses produksi oksigen terlarut didapatkan melalui mekanisme fotosintesis, difusi udara, penggunaan kincir air dan agitasi penambahan air baru pada saat dilakukan pergantian air di tambak (Prasad et al., 2014; Sanjou et al., 2018). Tingkat produksi oksigen terlarut malalui mekanisme fotosintesis yang

\section{Cite this as:}

Ariadi, H., Wafi, A., Supriatna \& Musa, M. (2021). Tingkat Difusi Oksigen selama Periode Blind Feeding Budidaya Intensif Udang Vaname (Litopenaeus vannamei). Rekayasa, 14 (2), 152-158.

doi: https://doi.org/10.21107/rekayasa.v14i2.10737 (c) 2021 Heri Ariadi, Abdul Wafi, Supriatna, Muhammad Musa 
berlangsung selama periode blind feeding diestimasi sebesar $1.51 \mathrm{mgO}_{2} / \mathrm{L} / \mathrm{Ha}$ (Vinatea et al., 2010). Sedangkan melalui proses penggunaan kincir air di tambak selama masa budidaya blind feeding, kapasitas produksi oksigen terlarut diestimasi sebanyak 1.4 $\mathrm{mgO}_{2} / \mathrm{L} / \mathrm{jam}$ dengan ukuran tambak seluas 0.18 $\mathrm{Ha}$ (Rahman et al., 2020).

Rasio estimasi produksi oksigen terlarut melalui mekanisme fotosintesis dan penggunaan kincir air tidak terpaut begitu jauh, karena kedua proses tersebut dipengaruhi oleh faktor biotik dan abiotik lingkungan perairan (Prasad et al., 2014). Kemudian untuk produksi oksigen terlarut yang ditimbulkan oleh proses agitasi dan produksi oksigen baru dari air yang masuk kedalam tambak melalui aktifitas pergantian air selama satu siklus budidaya diperoleh sekitar 0.6$0.8 \mathrm{mgO}_{2} / \mathrm{L} / \mathrm{Ha}$ atau sangat minim sekali (Hopkins et al., 1993). Sementara untuk mekanisme difusi oksigen dari hasil penelitian terdahulu oleh Madenjian, (1987) diperoleh tingkat produksi oksigen terlarut secara diurnal pada malam hari rata-rata sebesar 0.4-0.8 $\mathrm{mgO}_{2} / \mathrm{L} /$ kolam.

Berdasarkan hasil kajian teori dan penelitian terdahulu, tujuan dari penelitian ini adalah untuk mengetahui tingkat difusi oksigen selama masa blind feeding budidaya intensif udang vaname ( $L$. vannamei) berlangsung. Tingkat difusi oksigen selama periode blind feeding pada riset ini akan dikorelasikan dengan kapasitas tingkat kelarutan oksigen yang ada di tambak, sehingga akan ditemukan titik kesimpulan secara teoritis bagaimana proses difusi oksigen pada ekosistem tambak dapat berfluktuasi secara dinamis.

\section{METODE PENELITIAN Penentuan lokasi}

Penelitian ini dilaksanakan di tambak intensif Desa Bayeman, Probolinggo, Jawa Timur dengan konsep penelitian desain kausal ex-pose facto. Penelitian dilakukan selama 30 hari pertama masa budidaya udang antara bulan April - Mei 2019 atau tepatnya pada saat masa blind feeding budidaya udang vanname (L. vannamei) berlangsung. Tambak penelitian berukuran 400 $\mathrm{m}^{2}$ dengan padat tebar $112 \mathrm{ekor} / \mathrm{m}^{2}$ yang dilengkapi kincir air sebanyak 2 buah dengan kapasitas 2 HP. Sedangkan, manajemen operasional pemeliharaan udang dilakukan berdasarkan standart cara budidaya udang yang baik dan benar (CBIB).

\section{Analisis Data}

Variabel penelitian yang diamati adalah tingkat difusi oksigen terlarut, $\mathrm{pH}$, salinitas, oksigen terlarut, dan suhu yang dilakukan pengukuran pada pukul $06.00,12.00$, dan 21.00 setiap 2 hari sekali selama 30 hari masa blind feeding. Konsentrasi oksigen terlarut dan suhu air tambak diukur dengan menggunakan $A Z$ Instrument DO Meter (Type AZ 8402), konsnetrasi $\mathrm{pH}$ air tambak diukur menggunakan HANNA pH tester (type HI98107), sementara kadar salinitas air tambak diamati menggunakan hand-refraktometer MASTER-S10 ATAGO. Untuk tingkat difusi oksigen dilakukan pengamatan dan perhitungan variabel penelitian berdasarkan persamaan Madenjian et al, (1987) sebagai berikut :

DIF $=\frac{\mathrm{KL}}{\mathrm{PD}}(\mathrm{SAT}(\mathrm{T})-\mathrm{D} 0)$

$\mathbf{K L}=0.0036\left(8.43 w^{0,5}-3.67 w+0.43 w^{2}\right)$

Dimana DIF adalah tingkat difusi oksigen $\left(\mathrm{mgO}_{2} / \mathrm{L} / \mathrm{jam}\right), \quad K L$ adalah koefisien transfer oksigen $(\mathrm{m} / \mathrm{h}), P D$ ialah kedalaman tambak, $S A T(T)$ merupakan tingkat saturasi oksigen pada suhu tambak, DO adalah konsentrasi oksigen terlarut $\left(\mathrm{mgO}_{2} / \mathrm{L}\right), w$ ialah kecepatan angin $(\mathrm{m} / \mathrm{s})$. Selanjutnya, untuk 0.0036 adalah koefisien difusi oksigen, 8.43 ialah faktor koreksi kecepatan angin, 3.67 adalah koefisien transfer difusi udara, dan 0.43 adalah faktor koreksi akibat turbulensi air. Kemudian, untuk mengetahui hubungan kadar oksigen terlarut dengan tingkat difusi, maka dilakukan analisa regresi linear sederhana dengan bantuan software SPSS ver.16.

\section{HASIL DAN PEMBAHASAN \\ Kualitas Air Budidaya}

Parameter kualitas air yang diamati pada penelitian ini adalah $\mathrm{pH}$, salinitas, oksigen terlarut, dan suhu yang dilakukan pengukuran sehari tiga kali (pagi, siang, dan malam) setiap dua hari sekali. Fluktuasi parameter kualitas air budidaya dapat dilihat pada Gambar 1. Pada masing-masing grafik kualitas air, fluktuasi parameter kualitas air digambarkan berjalan dinamis sepanjang waktu pengamatan. Kualitas air adalah indikator lingkungan yang memiliki pola dan dinamika yang bervariasi untuk setiap waktunya (Ariadi et al., 2019). 

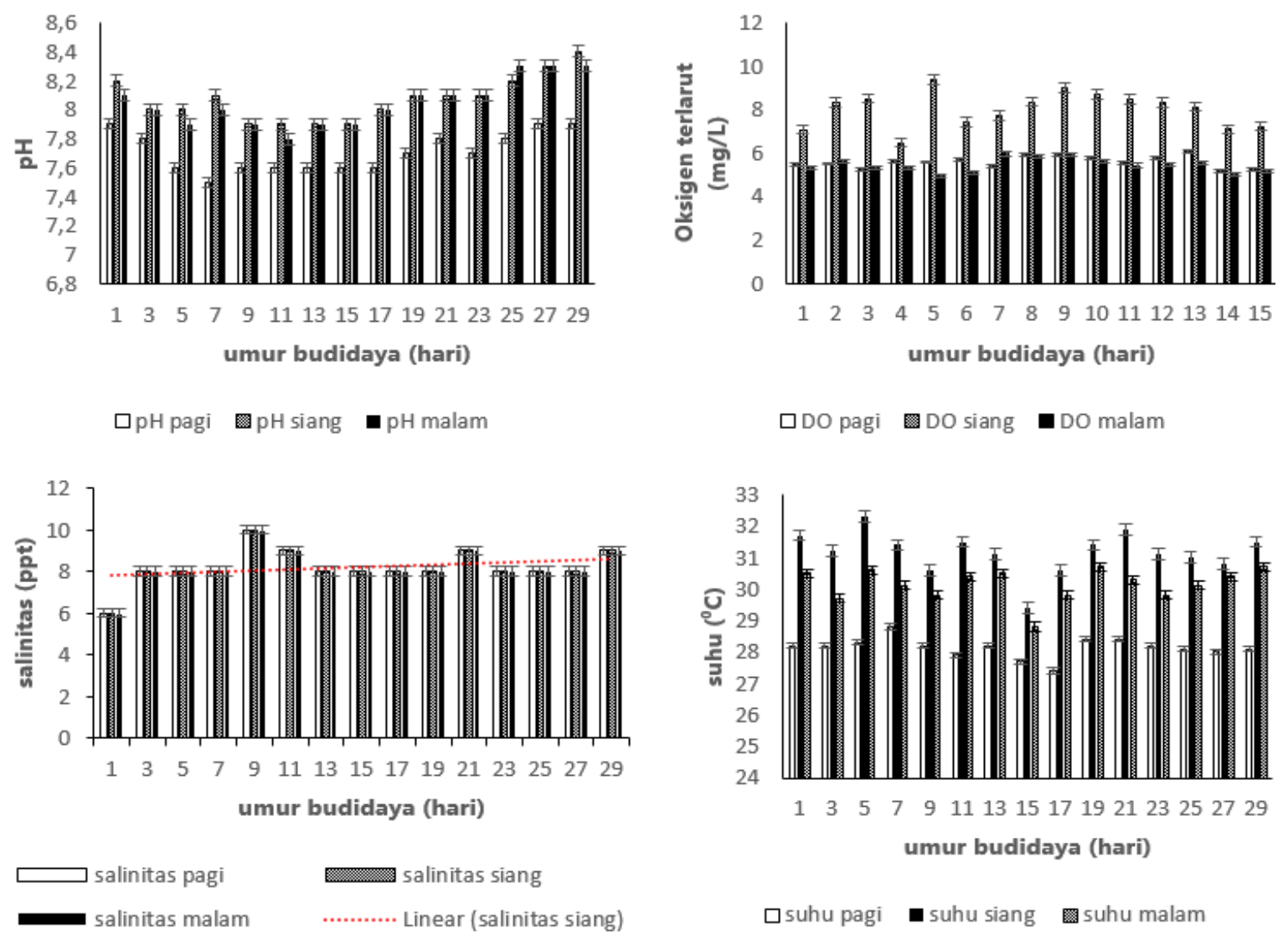

Gambar 1. Parameter Kualitas Air selama Masa Blind Feeding Budidaya

Pada grafik oksigen terlarut, digambarkan bahwa titik tertinggi konsentrasi oksigen di tambak terjadi pada siang hari. Kondisi ini, memiliki korelasi dengan data fluktuasi suhu tambak. Hal ini sesuai dengan pendapat Ren et al, (2018), bahwa konsentrasi suhu berpengaruh sangat signifikan terhadap kelarutan oksigen di perairan. Karakter fluktuasi DO dan suhu perairan sangat perlu dipahami sebagai modal untuk pengelolaan kualitas air tambak budidaya (Culberson dan Piedrahita, 1996). Sementara itu, untuk parameter salinitas air selama tiga kali periode waktu pengukuran (pagi, siang, malam) diketemukan memiliki kadar yang sama dan relatif stabil sepanjang waktu.

Selama masa blind feeding kadar oksigen terlarut cukup baik untuk budidaya udang intensif yaitu $>4 \mathrm{mg} / \mathrm{L}$. Tingginya kadar oksigen terlarut di tambak disebabkan oleh kadar salinitas air tambak yang tergolong rendah untuk budidaya air payau (<12 ppt). Kadar salinitas yang semakin rendah membuat tingkat transfer oksigen di perairan akan semakin meningkat, karena adanya perbedaan viskositas dan tingkat kelarutan zat cair (Fast et al., 1999; Edhy et al., 2010). Secara keseluruhan, kondisi parameter kualitas air selama masa blind feeding masih cukup baik dan mendukung untuk keperluan budidaya udang pola intensif.

\section{Kelarutan Oksigen Terlarut di Tambak}

Tingkat kelarutan oksigen di tambak selama 24 jam dapat dilihat pada grafik Gambar 2. Fluktuasi tingkat kelarutan oksigen di tambak mencapai konsentrasi tertinggi pada pukul 12.00 dengan konsentrasi DO 8.33 mg/L. Selanjutnya kadar oksigen terus menurun dan mencapai titik terendah pada pukul 21.00 dengan nilai konsentrasi $3.88 \mathrm{mg} / \mathrm{L}$. Kadar oksigen terlarut yang begitu rendah pada malam hari, disebabkan karena tidak adanya proses fotosintesis serta tingginya tingkat respirasi oleh organisme di perairan tambak (Boyd et al., 1978; Supriatna et al., 2017). 


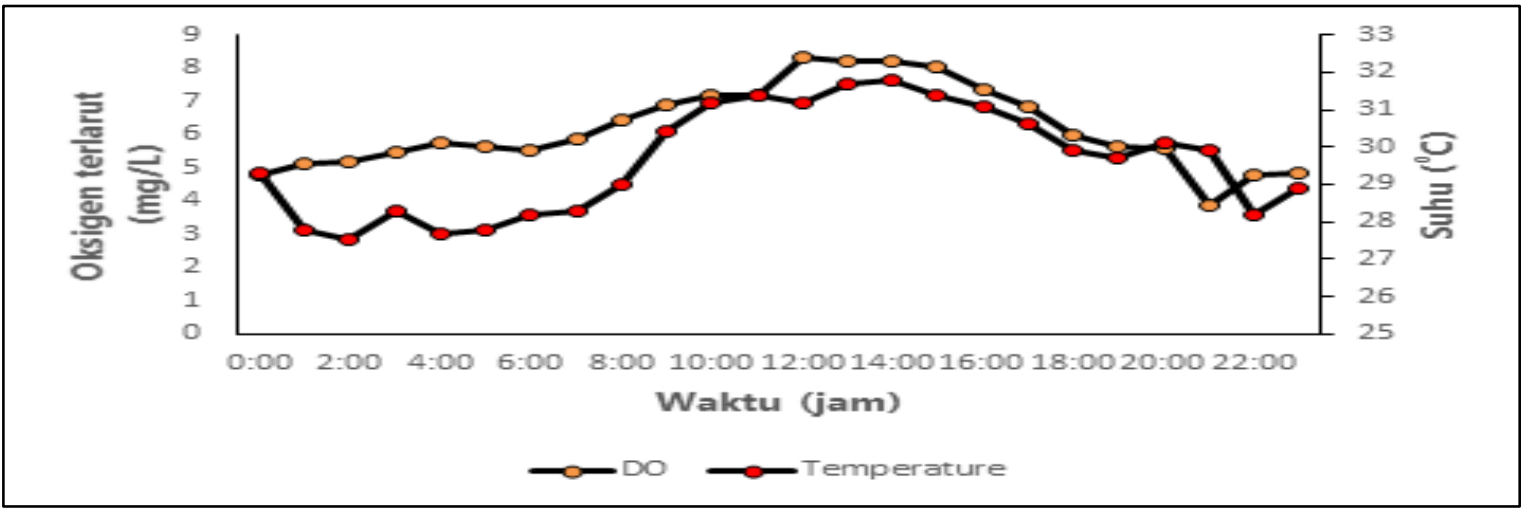

Gambar 2. Fluktuasi diurnal oksigen terlarut di tambak pada saat periode blind feeding

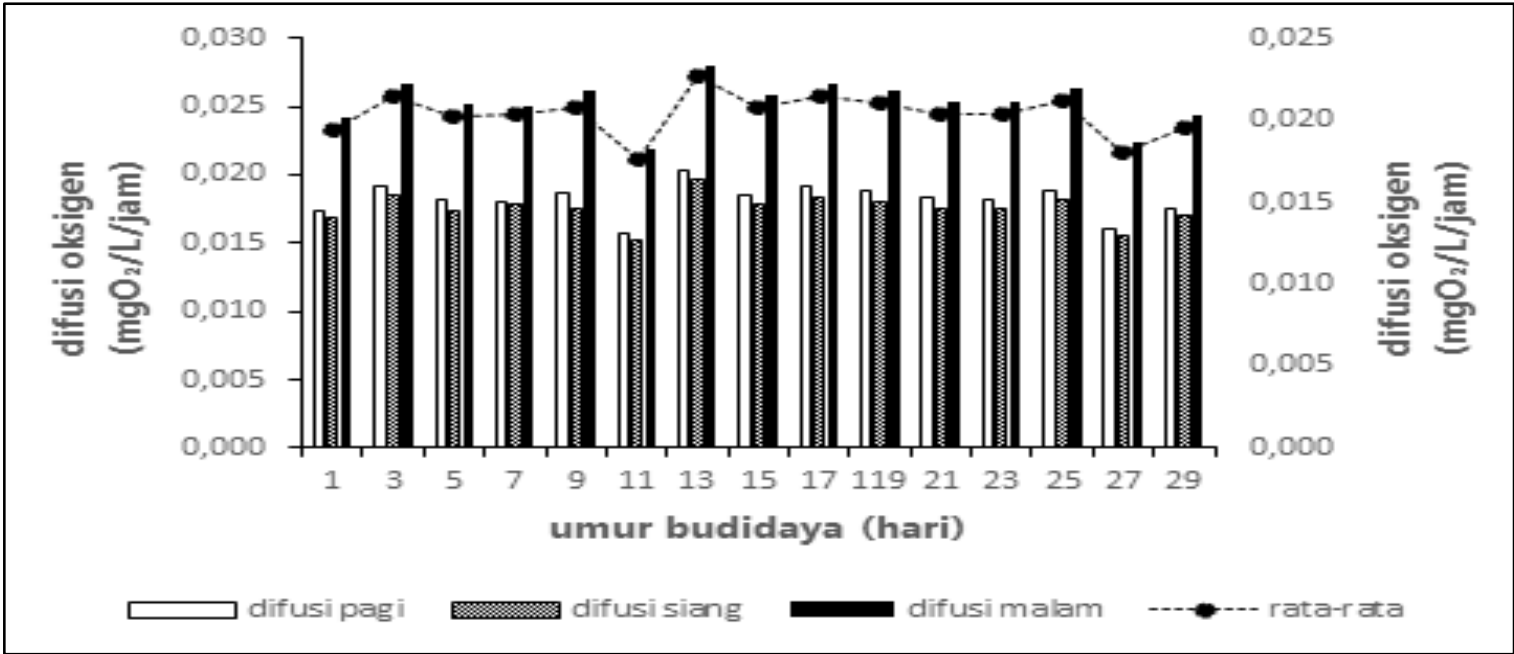

Gambar 3. Tingkat Difusi Oksigen selama Periode Blind Feeding Budidaya

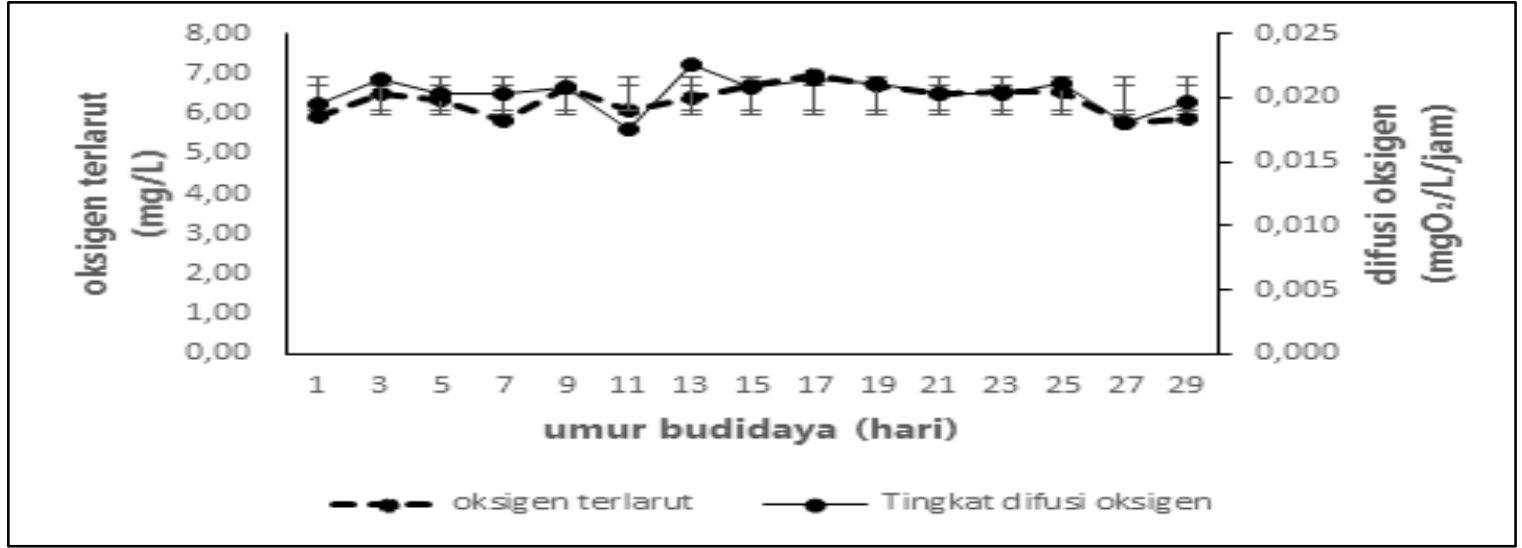

Gambar 4. Hubungan antara tingkat difusi terhadap kelarutan oksigen di tambak

Tingkat Difusi Oksigen Selama Blind feeding

Sepanjang periode blind feeding, tingkat difusi oksigen berjalan fluktuatif stabil (Gambar 3). Difusi oksigen berjalan secara dinamis dengan kisaran tingkat difusi $0.015-0.028 \mathrm{mgO}_{2} / \mathrm{L} / \mathrm{jam}$. Berdasarkan grafik tingkat difusi oksigen, terlihat bahwa tingkat tertinggi difusi oksigen di tambak terjadi pada waktu malam hari. Kenaikan tingkat difusi oksigen yang dominan pada malam hari, disebabkan oleh adanya perbedaan tekanan dan suhu antara udara dan kolom air. Adanya perbedaan suhu serta tekanan pada kolom air dan udara disebabkan oleh laju kecepatan angin di udara yang lebih kencang (Madenjian et al, 1987). Pada tambak perairan tawar atau payau, tingkat difusi udara sangat erat dipengaruhi oleh laju kecepatan angin (Madenjian et al., 1988).

Untuk mendukung proses difusi dapat berjalan optimal, maka pada malam hari perlu dioperasikan kincir air yang sesuai dengan 
kapasitas daya dukung tambak. Dengan adanya kincir air diharapkan terjadi proses reaerasi pada permukaan tambak, sehingga aktifitas difusi oksigen dapat berjalan optimal (Boyd dan Teichert-Coddington, 1992). Selain itu, dengan penggunaan kincir air diharapkan terjadi proses augmentasi oksigen secara natural di tambak pada saat kondisi DO rendah (Boyd, 1998). Secara umum, selain penggunaan kincir air, efektifitas transfer difusi oksigen di tambak juga dipengaruhi oleh struktur geometri, kedalaman tambak, dan kondisi kualitas air tambak (Garcia dan Brune, 1991; Rogers et al., 1991). Sehingga, penentuan desain lay out tambak dan pengunaan alat perekayasa budidaya sangat memainkan peranan penting pada saat proses difusi berlangsung.

\section{Hubungan Tingkat Difusi Dengan Kelarutan Oksigen di Tambak}

Oksigen terlarut adalah parameter kunci dalam pengelolaan tambak budidaya (Boyd dan Teichert-Coddington, 1992). Sementara difusi, merupakan salah satu mekanisme dari produksi oksigen di tambak. Hubungan antara tingkat difusi terhadap kelarutan oksigen di perairan tambak dapat dilihat pada Gambar 4. Berdasarkan grafik tersebut, rerata fluktuasi harian kelarutan oksigen dan tingkat difusi cenderung stabil. Begitu juga, trend fluktuasi DO dan difusi cenderung sama secara diurnal. Pada ekosistem tambak, difusi adalah salah satu faktor pembatas dalam neraca produksi oksigen di perairan (Garcia dan Brune, 1991). Data fluktuasi harian dari proses difusi dapat digunakan sebagai acuan umum untuk strategi pengelolaan lingkungan perairan (Daigh et al., 2014).

Hubungan antara tingkat difusi terhadap kelarutan oksigen di tambak digambarkan dengan model regresi $Y=0.006+0.002 x$. Artinya, setiap kenaikan transfer difusi sebesar 1 $\mathrm{mgO}_{2} / \mathrm{L} / \mathrm{jam}$, maka akan terjadi penambahan oksigen di tambak sebanyak 0.002 mg/L. Gradien kelarutan DO sangat dipengaruhi oleh kondisi parameter fisika-kimia perairan tambak (Supriatna et al., 2017). Kondisi ini, memungkinkan untuk menjadikan mekanisme difusi dan respirasi sebagai model deviasi untuk menentukan fluktuasi harian kelarutan kadar oksigen di tambak (Madenjian et al., 1987). Kelarutan gas oksigen dari udara menuju media perairan akan berpindah mengikuti derajat koefisien termal suhu di perairan (Ariadi et al., 2019; Varalda et al., 2019). Difusi oksigen bersifat dinamis mengikuti dinamika fluktuasi kualitas air dan tekanan hidrodinamis yang ada di perairan tambak (Reiser et al., 2020).

Secara keseluruhan, trend fluktuasi tingkat difusi oksigen selama masa blind feeding budidaya berjalan secara normal. Keadaan tersebut diikuti dengan kondisi kualitas air yang stabil sepanjang periode budidaya. Tingkat difusi oksigen selama periode blind feeding budidaya udang vaname diketemukan rata-rata sebesar $0.020 \mathrm{mgO}_{2} / \mathrm{L} / \mathrm{jam}$. Mekanisme difusi oksigen adalah faktor pembatas produksi oksigen di perairan yang secara matematis berpengaruh terhadap kuantitas serta beban kelarutan kadar oksigen secara keseluruhan pada suatu media perairan (Reiser et al., 2020). Secara umum, proses difusi oksigen di tambak dipengaruhi oleh beragam faktor. Faktor-faktor yang berpengaruh tersebut diantaranya adalah struktur geometri tambak, luas dan kedalaman tambak, kondisi kualitas air, turbulensi, tekanan udara, serta penggunaan kincir air (Rogers et al., 1991; Fast et al., 1999). Tingkat difusi oksigen memiliki peran yang tidak begitu vital terhadap proses produksi oksigen di tambak, tetapi secara keseluruhan proses difusi oksigen merupakan salah satu komponen yang tidak bisa dilepaskan dari proporsi rasio kebutuhan oxygen budget di perairan (Tomaso dan Najjar, 2015).

\section{KESIMPULAN DAN SARAN Kesimpulan}

Kesimpulan dari penelitian ini, tingkat difusi oksigen selama periode blind feeding budidaya intensif udang vaname (Litopenaeus vannamei) diperoleh rata-rata sebesar $0.020 \mathrm{mgO}_{2} / \mathrm{L} / \mathrm{jam}$, dari rentang $0.018-0.023 \mathrm{mgO}_{2} / \mathrm{L} / \mathrm{jam}$ selama 30 hari masa budidaya.

\section{Saran}

Berdasarkan hasil dari penelitian ini, diharapkan dapat dikembangkan riset ke tahap selanjutnya mengenai kajian mekanisme, dinamika, serta pengaruh difusi oksigen terhadap ekologi tambak budidaya udang intensif.

\section{DAFTAR PUSTAKA}

Ariadi, H., Fadjar, M., Mahmudi, M., dan Supriatna. (2019). The relationships between 
water quality parameters and the growth rate of white shrimp (Litopenaeus vannamei) in intensive ponds. AACL Bioflux, 12(6), 2103-2116.

Ariadi, H., Wafi, A., dan Supriatna. (2020). Hubungan Kualitas Air Dengan Nilai FCR Pada Budidaya Intensif Udang Vanname (Litopenaeus vannamei). Samakia: Jurnal Ilmu Perikanan, 11 (1), 44-50.

Boyd, C.E. (1998). Pond water aeration systems. Aquacultural Engineering, 18, 9-40.

Boyd, C.E., Romaire, R.P., dan Johnston, E. (1978). Predicting early morning dissolved oxygen concentrations in channel catfish ponds. Transactions of the American Fisheries Society, 107(3), 484-492.

Boyd, C.E., dan Teichert-Coddington, D. (1992). Relationship between wind speed and reaeration in small aquaculture ponds. Aquacultural Engineering, 11, 121-131.

Culberson, A.D., dan Piedrahita, R.H. (1996). Aquaculture pond ecosystem model: temperature and dissolved oxygen prediction - mechanism and application. Ecological Modelling, 89, 231-258.

Daigh, A.L., Sauer, T.J., Xiao, X., dan Horton, R. (2014). Spatial and Temporal Dynamics of Soil-Surface Carbon Dioxide Emissions in Bioenergy Corn Rotations and Reconstructed Prairies. Soil Science Society of America Journal, 78, 1338-1350.

Edhy, W.A., Azhary, K., Pribadi, J., Chaeruddin, M.K. (2010). Budidaya udang putih (Litopenaeus vannamei.Boone, 1931). Jakarta: CV. Mulia Indah.

Fast, A.W., Tan, E.C., Stevens, D.F., Olson, J.C., Qin, J., Barclay, D.K. (1999). Paddlewheel aerator oxygen transfer efficiencies at three salinities. Aquacultural Engineering, 19, 99103.

Garcia, A., dan Brune, D.E. (1991). Transport limitation of oxygen in shrimp culture ponds. Aquacultural Engineering, 10, 269279.

Hopkins, J.S., Hamilton, R.D., Sandifer, P.A., Browdy, C.L., dan Stokes, A.D. (1993). Effect of Water Exchange Rate on Production, Water Quality, Effluent Characteristics and
Nitrogen Budgets of Intensive Shrimp Ponds. Journal of The World Aquaculture Society, 24(3), 304-320.

Madenjian, C.P., Rogers, G.L., dan Fast A.W. (1987). Predicting night time dissolved oxygen loss in prawn ponds of Hawaii: Part I. Evaluation of traditional methods. Aquacultural Engineering, 6, 191-208.

Madenjian, C.P., Rogers, G.L., dan Fast A.W. (1987). Predicting night time dissolved oxygen loss in prawn ponds of Hawaii: Part II. A new methods. Aquacultural Engineering, 6, 209-225.

Madenjian, C.P., Rogers, G.L., dan Fast A.W. (1988). Predicting night time dissolved oxygen loss in aquaculture ponds. Can. J. fish. Aquat. Sci., 45, 1842-1847

Prasad, B.S.R.V., Srinivasu, P.D.N., Varma, P.S., Raman, A.V., dan Ray, S. (2014). Dynamics of dissolved oxygen in relation to saturation and health of an aquatic body: A case for Chilka Lagoon, India. Journal of Ecosystems, 2014,

1-14. http://dx.doi.org/10.1155/2014/526245.

Rahman, A., Dabrowski, J., dan McCulloch, J. (2020). Dissolved oxygen prediction in prawn ponds from a group of one step predictors. Information Processing in Agriculture, 7(2), 307-317.

Rajwa-Kuligiewicz, A., Bialik, R.J., dan Rowinski, P.M. (2015). Dissolved oxygen and water temperature dynamics in lowland rivers over various timescales. J. Hydrol. Hydromech, 63(4), 353-363.

Reiser, R., Stadelmann, V., Weisskopf, P., Grahm, L., dan Keller, T. (2020). System for quasicontinuous simultaneous measurement of oxygen diffusion rate and redox potential in soil. Journal of Plant Nutrition and Soil Science, 183(3), 1-11.

Ren, Q., Zhang, L., Wei, Y., dan Li, D. (2018). A method for predicting dissolved oxygen in aquaculture water in an aquaponics system. Computers and Electronics in Agriculture, 151, 384-391.

Rogers, G.L., Madenjian, C.P., dan Fast, A.W. (1991). Estimation of oxygen transfer rates for mechanical aerators in brackishwater 
aquaculture ponds. Journal of Applied Aquaculture, 1(2), 63-78. http://dx.doi.org/10.1300/J028v01n02_04

Sanjou, M., Okamoto, T., dan Nezu, I. (2018). Dissolved oxygen transfer into a square embayment connected to an open-channel flow. International Journal of Heat and Mass Transfer, 125, 1169-1180.

Supriatna., Marsoedi., Hariati, A.M., Mahmudi, M. (2017). Dissolved oxygen models in intensive culture of whiteleg shrimp, Litopenaeus vannamei, in East Java, Indonesia. AACL Bioflux, 10(4), 768-778.

Syah, R., Makmur., dan Fahrur, M. (2017). Budidaya udang vaname dengan padat penebaran tinggi. Media Akuakultur, 12(1), 19-26.

http://ejournalbalitbang.kkp.go.id/index.php/m.

Tomaso, D.J., dan Najjar, R.G. (2014). Long-term variations in the dissolved oxygen budget of an urbanized tidal river: The upper Delaware Estuary. Journal of Geophysical Research: Biogeosciences, 120, 1027-1045. doi:10.1002/2014JG002758.

Veralda, J., Dartora, C.A., de Camargo, P.C., de Oliveira, J.A., dan Mosca, D.H. (2019). Oxygen diffusion and vacancy migration thermally-activated govern hightemperature magnetism in ceria. Scientific Reports, 9, 1-9.

Vinatea, L., Galvez, A.O., Browdy, C.L., Stokes, A., Venero, J., Haveman, J., Lewis, B.L., Lawson, A., Shuler, A., dan Leffler, J.W. (2010). Photosynthesis, water respiration and growth performance of Litopenaeus vannamei in a super-intensive raceway culture with zero water exchange: Interaction of water quality variables. Aquacultural Engineering, 42, 17-24. 